\title{
The role of reality monitoring in anosognosia for hemiplegia
}

\author{
Paul M. Jenkinson ${ }^{\mathrm{a}, *}$, Nicola M. J. Edelstyn ${ }^{\mathrm{b}, \mathrm{c}}$, Justine L. Drakeford ${ }^{\mathrm{d}}$, Christine Roffe ${ }^{\mathrm{c}}$ and \\ Simon J. Ellis ${ }^{\mathrm{e}}$

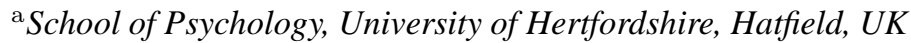 \\ ${ }^{\mathrm{b}}$ School of Psychology, Keele University, Keele, UK \\ ${ }^{\mathrm{c}}$ Research Institute for Life Course Studies, Keele University, Keele, UK \\ ${ }^{\mathrm{d}}$ School of Human and Health Sciences, University of Huddersfield, Huddersfield, UK \\ ${ }^{\mathrm{e}}$ Department of Neurology, University Hospital of North Staffordshire, Stoke-On-Trent, UK
}

\section{Introduction}

Anosognosia for hemiplegia (AHP) refers to a lack of awareness regarding paralysis after stroke. Despite attracting clinical interest for decades, empirical research into AHP has been relatively scarce, and there remains no universally accepted explanation [5]. This is partially due to difficulty characterising the disorder. The term has been applied to both partial and complete lack of awareness, with partial unawareness presenting as a failure to recognise, appreciate the severity, or acknowledge the consequences of paralysis, and more complete cases involving a failure to admit the presence of a paralysis even after its demonstration [8]. The fact that some patients verbally deny their problems, but show behaviours consistent with their paralysis (e.g. executing a bi-manual tasks using a unimanual strategy), while others verbally accept their paralysis but behave in a manner inconsistent with this acceptance (e.g. attempting to walk), suggests that verbal and behavioural awareness are independent [4]. The observation of diverse lesion sites, emotional, perceptual, and cognitive impairments in anosognosia has also resulted in unawareness being considered a multifaceted or

*Corresponding author: Dr. Paul Jenkinson, School of Psychologym, University of Hertfordshire, Hatfield, AL10 9AB, UK. E-mail: dr.paul.jenkinson@gmail.com. multicomponent disorder involving several subtypes [4, $8,10]$. As such, different forms of anosognosia may reflect the combination of various deficits, the exact components of which are not currently known [10].

Recent accounts of AHP have employed a model of the motor system, which proposes that awareness involves a comparison of predicted and actual sensory information (Fig. 1). It is suggested that AHP patients fail to register discrepancy between internal sensory predictions and external sensory information [1, 3]. This results in an erroneous feeling of having performed intended movements using the paralysed limb. Recent experiments in AHP support this idea; however, a purely motor account cannot explain several aspects of AHP, such as its delusional character (e.g. resilience to counterargument) and associated affective disturbance [5]. It is likely that other neurocognitive disturbances also contribute to AHP. On the basis of research in other delusional patients [2], and a speculated reality monitoring impairment in an AHP casereport [9], we hypothesised that an inability to discriminate between internally- and externally-generated information (i.e. reality monitor) would contribute to AHP.

We conducted two experiments to examine this proposal [6]. Experiment 1 employed a classic reality monitoring paradigm [7], to test the ability to discriminate between seen (perceived) and imagined drawings of objects in AHP patients $(n=10)$, hemiplegic con- 


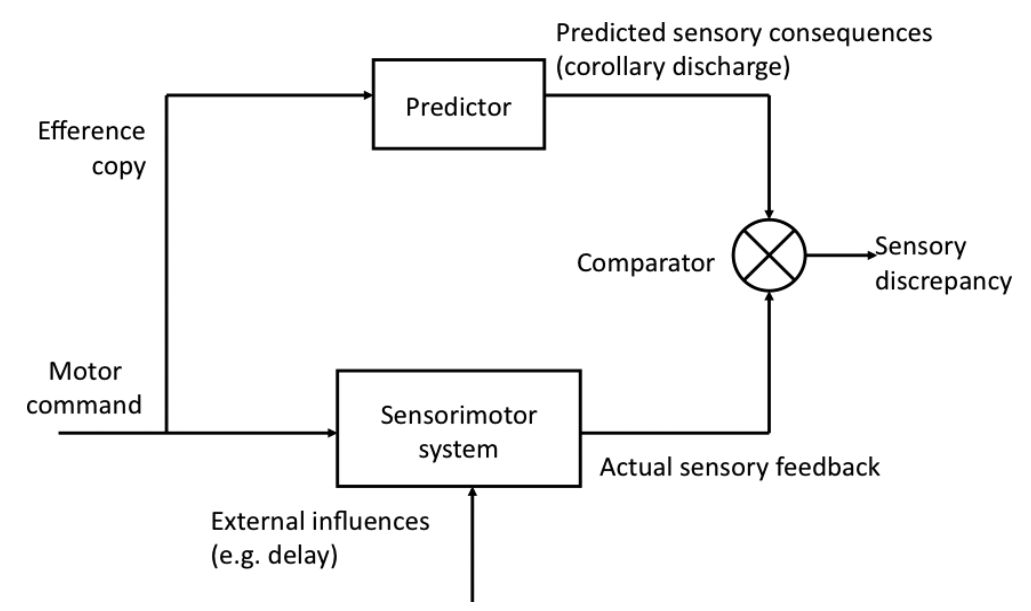

Fig. 1. A simple model of the motor system adapted from Frith et al. [3]. Actual and predicted sensory information are compared to generate a sensory discrepancy which signals movement error.

trol patients without AHP (nonAHP, $n=7$ ) and agematched healthy controls (HC, $n=20)$. During a study phase, subjects were presented with a word (e.g. PEN) followed by either: (i) a picture representing the object (i.e. drawing of a pen), or (ii) an empty circle into which they projected a mental picture of the previous word (i.e. imagine a drawing of a pen). In a test phase, subjects saw previously studied (target) and unstudied (new) words, and had to decide if each word had been studied previously. Following this, words identified as previously studied were assessed in terms of the source of the original image (i.e. "Did you previously see or imagine a drawing of a [PEN]?"). AHP patients were significantly impaired at this task relative to $\mathrm{HCs}$ (omnibus Kruskal-Wallis test $H(2)=21.23, p<0.001$ ) and nonAHP patients (post-hoc Mann-Whitney $U=6, p=$ 0.006), indicating a deficit in discriminating the source of images as real/imagined.

A second experiment explored if this reality monitoring deficit occurs in the motor domain. Adapting the procedure of Experiment 1, AHP $(n=3)$, nonAHP $(n=6)$, and HC $(n=20)$ subjects were presented orally with action phrases (e.g. point to the door), which they either had to execute themselves (perform item), imagine executing (imagine item), or observe the experimenter executing (observe item). The ability to discriminate studied/unstudied phrases, and make source judgements was then assessed using the procedure of Experiment 1 (e.g. "Did you previously [perform/imagine/observe] pointing to the door?"). Results again indicated impaired reality monitoring in patients with AHP compared with HCs $(H(2)=11.54, p=$ $0.001)$ and nonAHP patients $(U=1, p=0.048)$. However, the ability to reality monitor movements was also impaired in nonAHP patients relative to HCs ( $U=24$, $p=0.026)$. Performance on the task showed a steady decline from $\mathrm{HC}$ levels, to mild impairment in nonAHP patients, and greatest impairment in AHP.

Findings of these two experiments suggest a combination of reality monitoring impairments in the pathogenesis of AHP. Experiment 1 showed that the ability to discriminate between real and imagined drawings was impaired in AHP patients only. Experiment 2 showed that the ability to monitor actions is deficient in both AHP and nonAHP patients, but is more impaired in patients with AHP. As such, impaired reality monitoring of movement might be a general consequence of damage to the motor system. From our results it is not possible to identify whether the processes responsible for greater impairment of action reality monitoring in AHP are the same as those underlying the deficit observed in nonAHP patients.

We speculate that this combination of reality monitoring deficits prevents AHP patients from checking the veracity of knowledge about the motor system and their current state generally. This is consistent with the $\mathrm{ABC}$ model [10], in which awareness relies on an ability to Check available information, in order to change one's Beliefs, and/or act upon signals of uncertainty arising from subjective Appreciation (experience) of a specific function (e.g. moving). This explanation readily accommodates recent motor explanations of AHP [1,3]: the erroneous belief that one is able to move may arise from a defective appreciation of paralysis, caused by impaired sensory feedback, and/or a failure to register discrepancies between motor intentions and sensory information. This explanation suggests that AHP can result from different deficits which combine to pro- 
duce the same clinical endpoint. As such, it is able to account for the multifaceted nature of AHP; however, further research is needed to identify the exact factors which produce AHP.

\section{References}

[1] A. Berti, L. Spinazzola, L. Pia, M. Rabuffetti, P. Haggard, Y. Rossetti et al., Motor awareness and motor intention in anosognosia for hemiplegia, in: Sensorimotor foundations of higher cognition, Oxford: Oxford University Press, 2007, pp. 163-181.

[2] G. Brébion, M. Smith, J. Gorman and X. Amador, Discrimination accuracy and decision biases in different types of reality monitoring in schizophrenia. Journal of Nervous and Mental Disease 185 (1997), 247-253.

[3] C.D. Frith, S.J. Blakemore and D.M. Wolpert, Abnormalities in the awareness and control of action. Philosophical Transactions of the Royal Society of London: Biological Sciences 355 (2000), 1771-1788.

[4] M. Jehkonen, M. Laihosalo and J. Kettunen, Anosognosia after stroke: Assessment, occurrence, subtypes and impact on functional outcome reviewed, Acta Neurologica Scandinavica 114 (2006), 293-306.

[5] P.M. Jenkinson and A. Fotopoulou, Motor awareness in anosognosia for hemiplegia: Experiments at last! Experimental Brain Research 204 (2010), 295-304.

[6] P.M. Jenkinson, N.M.J. Edelstyn, J.L. Drakeford and S.J. Ellis, Reality monitoring in anosognosia for hemiplegia, Consciousness and Cognition 18 (2009), 458-470.

[7] M.K. Johnson, Reality monitoring: Evidence from confabulation in organic brain disease patients, in: Awareness of deficit after brain injury: Clinical and theoretical issues, G.P. Prigatano and D.L. Schacter, eds, New York: Oxford University Press, 1991, pp. 176-197.

[8] M.D. Orfei, R.G. Robinson, G.P. Prigatano, S. Starkstein, N. Rüsch, P. Bria et al., Anosognosia for hemiplegia after stroke is a multifaceted phenomenon: A systematic review of the literature, Brain 130(12) (2007), 3075-3090.

[9] A. Venneri and M.F. Shanks, Belief and awareness: reflections on a case of persistent anosognosia, Neuropsychologia 42 (2004), 230-238.

[10] R. Vocat and P. Vuilleumier, Neuroanatomy of impaired body awareness in anosognosia and hysteria: A multicomponent account, in: The study of anosognosia, G. Prigatano, ed., New York, USA: Oxford University Press, 2010, pp. 359-403. 


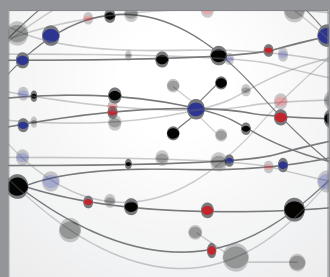

The Scientific World Journal
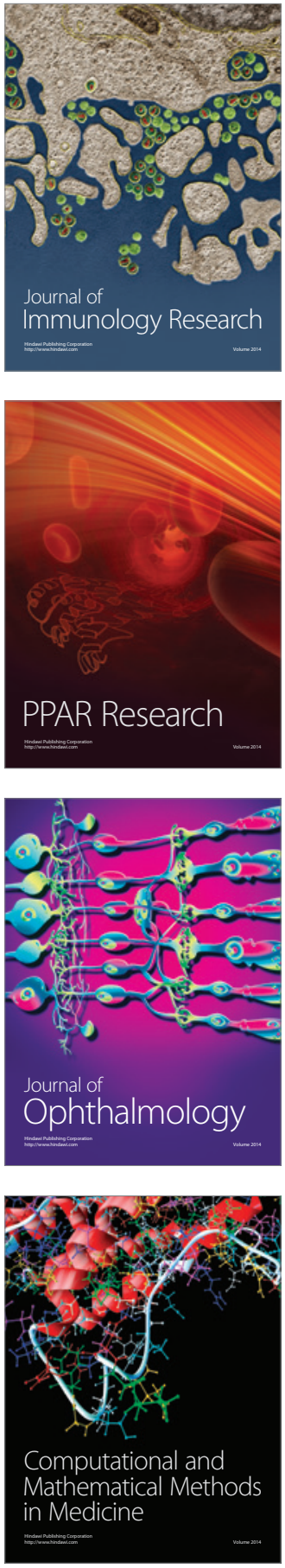

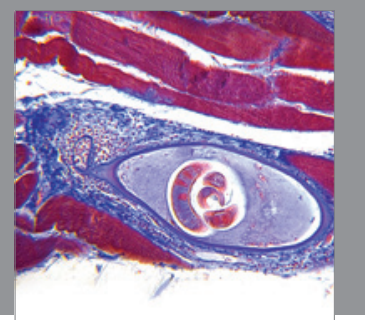

Gastroenterology

Research and Practice
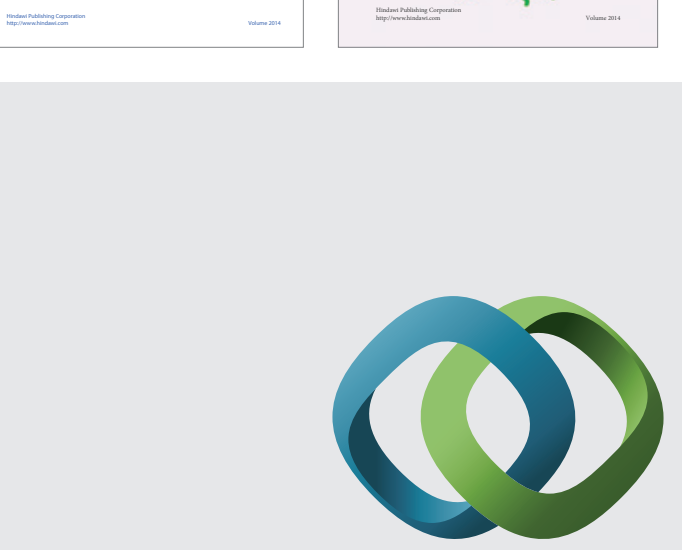

\section{Hindawi}

Submit your manuscripts at

http://www.hindawi.com
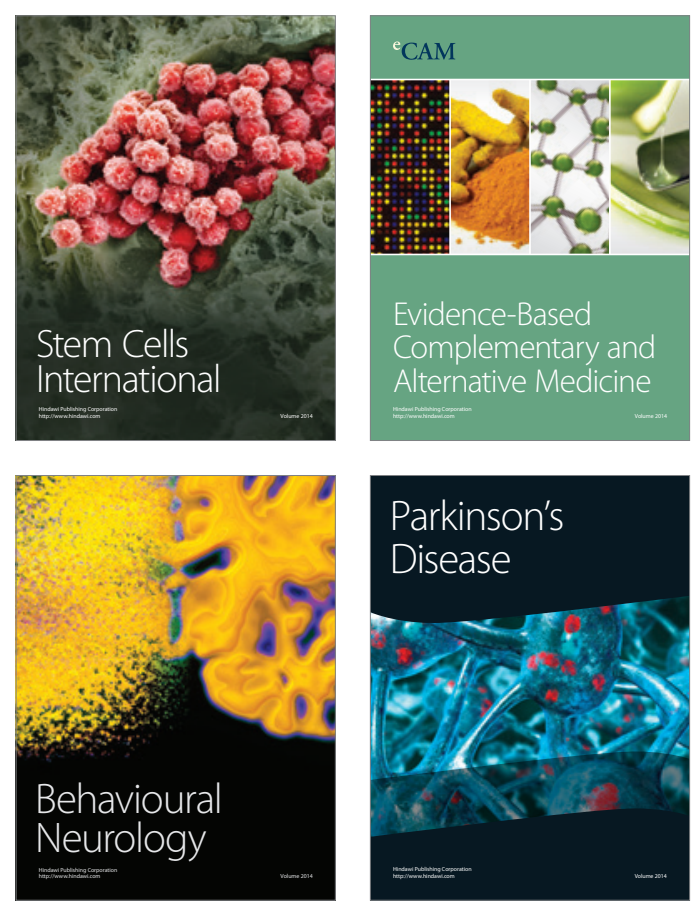

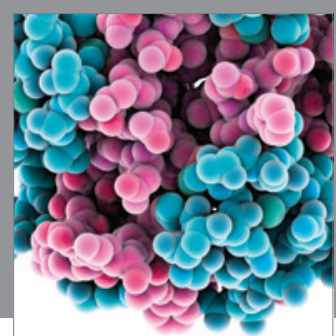

Journal of
Diabetes Research

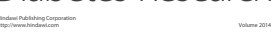

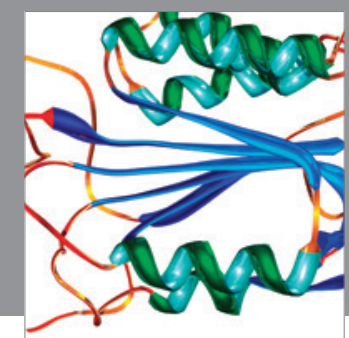

Disease Markers
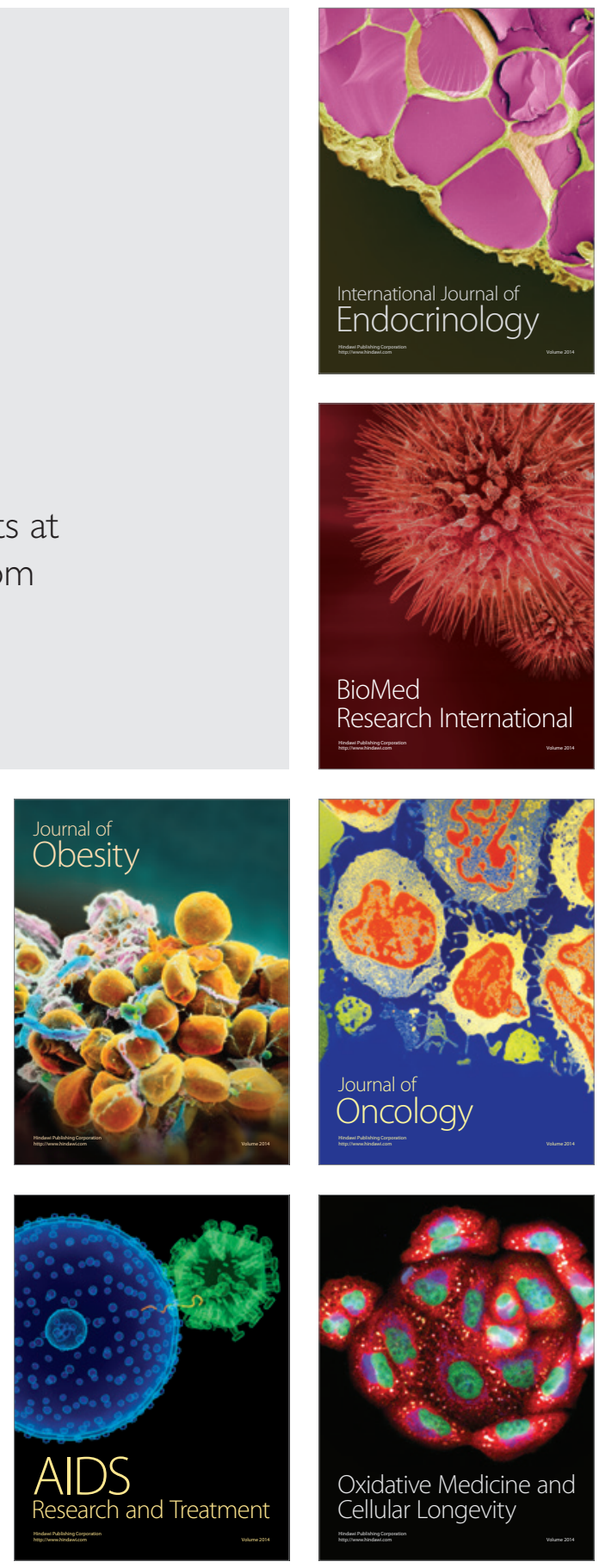